\title{
REFLEXÕES SOBRE A ALTERIDADE NA EXPRESSÃO POÉTICA DE CHARLES TROCATE
}

\author{
Airton Souza Oliveira ${ }^{1}$ \\ Gilson Penalva ${ }^{2}$
}

\begin{abstract}
Resumo: Esse trabalho apresenta uma análise a respeito das reflexões sobre a alteridade, centrada na obra Conversa com louças, do poeta amazônida Charles Trocate. Na nossa análise iremos mostrar como os discursos coloniais projetaram formas de imposições a fim de criar um pensamento homogêneo dentro das Amazônias e, como a expressão poética trocatiana, produzida na Amazônia Oriental foi aos poucos contribuindo para descontruir esse processo. Nossos referenciais teóricos se encontrarão em importantes obras teóricas ligadas ao pensamento contemporâneo sobre identidade e cultura, entre os quais BHABHA (1998); HALL (2011); SPIVAK (2014) e PENALVA (2012).
\end{abstract}

Palavras-chave: Alteridade. Poesia e Poética de expressão Amazônica.

\section{REFLECTIONS ON OTHERNESS IN THE POETIC EXPRESSION OF CHARLES TROCATE}

\begin{abstract}
This work presents an analysis of the reflections on alterity, centered on the work Conversa com louças, by the Amazonian poet Charles Trocate. In our analysis we will show how the colonial discourses designed forms of impositions in order to create a homogeneous thought within the Amazon and, as the poetic expression produced in the Eastern Amazon was little by little contributing to deconstruct this process. Our theoretical references will be found in important theoretical works linked to contemporary thinking about identity and culture, among which BHABHA (1998); HALL (2014); SPIVAK (2014) and PENALVA (2012).

Keywords: Other. Poetry and Poetics of Amazonian expression. \section{CHARLES TROCATE}

REFLEXIONES SOBRE LA ALTERIDAD EN LA EXPRESIÓN POÉTICA DE
\end{abstract}

Resumen: Este trabajo presenta un análisis de las reflexiones sobre la alteridad, centrado en la obra Conversa com louças (Charla con platos), del poeta amazónico Charles Trocate. En nuestro análisis mostraremos cómo los discursos coloniales proyectaron formas de imposición para crear un pensamiento homogéneo dentro de la Amazonía y, como la expresión poética trocatiana, producida en la Amazonía oriental fue contribuyendo a deconstruir este proceso. Nuestras referencias teóricas se encontrarán en importantes trabajos teóricos vinculados al pensamiento contemporáneo sobre la identidad y la cultura, entre los que destacan BHABHA (1998); HALL (2011); SPIVAK (2014) y PENALVA (2012).

Palabras clave: Alteridad. Poesía y Poética de la expresión amazónica.

\section{Introdução}

\footnotetext{
${ }^{1}$ Mestre em Letras, pelo Programa de Pós-graduação do Instituto de Linguística, Letras e Artes - ILLA, da Universidade Federal do Sul e Sudeste do Pará (Unifesspa). Possui 34 livros publicados e participação em mais de 90 antologias. Já venceu mais de 50 prêmios literários e coordena importantes projetos na área da leitura, de acesso ao livro e a literatura na região do sul e sudeste do Pará, entre os quais o Prêmio Amazônia de Literatura e o Projeto Tocaiunas. Atualmente é professor efetivo da disciplina de História, do quadro efetivo da rede de ensino do município de Itupiranga.

${ }^{2}$ Doutor em Letras pela Universidade Federal da Paraíba - UFPB. Professor Adjunto e Diretor do Instituto de Linguística, Letras e Artes - ILLA - da Universidade Federal do Sul e Sudeste do Pará - UNIFESSPA.
} 
Está entre as marcas mais significativas e simbólicas do que comumente vem sendo denominado de pós-modernidade o reconhecimento relacionado à compreensão dos valores em torno da diferença. Sendo, portanto, problematizado e questionado, por exemplo, a relação de compreensão de mundo a partir do binarismo, da fixidez de uma única verdade, da homogeneidade e na imposição de uma essencialidade sobre o ser e, no caso da Amazônia, também sobre o espaço amazônico.

Além disso, nessa pós-modernidade estão também sendo colocadas importantes questões em torno da representação discursiva sobre o falacioso discurso fundador e supostamente originário postulado pela metafísica ocidental; questões epistemológicas e metodológicas questionando a teoria literária tradicional, da própria crítica e, principalmente a classificação ou imposição identitária do outro.

Assim, uma gama de pensamentos teóricos da pós-modernidade contribui de certa forma para interrogar e suplantar o processo histórico homogêneo sobre a identidade e a alteridade. Esses processos, postulados e impostos por uma lógica eurocêntrica, foram denominados por Homi K. Bhabha de subjetividades originárias, ou seja, a metafísica ocidental e seus discursos coloniais, que foram projetados como verdade única para diversos povos, principalmente os colonizados que são tão complexos e heterogêneos.

Vale ressaltar que essas compreensões e deslocamentos epistemológicos não atuam meramente como uma marca ou qualidade de negação. Ou ainda para servir como mantenedora de uma posição de poder a validar uma relação dicotômica na atribuição do valor relacional entre o eu e o outro, pois, com isso ultrapassa-se o processo de assimilação, tão preterido pelo pensamento ocidental e rompe-se todo o projeto de homogeneização imposto historicamente pela metafísica ocidental e seu pensamento eurocêntrico. Dessa forma, o outro encontra-se agora revertido por valores que foram historicamente silenciados, soterrados dentro do procedimento homogeneamente eurocêntrico.

Neste caso, os valores agora passam a ser marcados pela problemática e complexidade da diferença e pelo reconhecimento das transformações estruturais, discursivas e epistemológicas, que juntos passaram a compreender a real existência de uma crise de representação e também identitária dos sujeitos. Sujeitos estes que antes estiveram na condição de subjugados e obrigatoriamente presos e submetidos a uma concepção formalmente homogênea e categorizada de forma monolítica, resultando em 
grande parte nos estereótipos, na estabilidade da identidade e nos exotismos. Segundo Stuart Hall é a partir de meados do século XX que,

Isso está fragmentando as paisagens culturais de classe, gênero, sexualidade, etnia, raça e nacionalidade, que, no passado, nos tinham fornecido sólidas localizações como indivíduos sociais. Estas transformações estão também mudando nossas identidades pessoais, abalando a ideia que temos de nós próprios como sujeitos integrados. Esta perda de um "sentido de si" estável é chamada, algumas vezes, de deslocamento ou descentração do sujeito. (HALL, 2011, p. 9).

Dessa forma, essa complexa crise do deslocamento ou de descentração do sujeito, por meio do processo descentralizador de uma suposta homogeneidade, postulada, como vimos, historicamente pela metafísica ocidental, na representação identitária do eu e do outro, contribuíram diretamente para os procedimentos de reconhecimento da alteridade. Isso fez com que, de alguma maneira, houvesse uma rasura, ao que hoje é "irredutivelmente heterogêneo" (SPIVAK, 2014, p. 13). O resultado imediato perpassou principalmente pela problematização de um suposto, ou para sermos mais coerentes, da imposição do Eu totalmente unificado e, que teve suas experiências históricas, culturais, sociais ocupadas por uma única premissa epistemológica sobre as relações nos estratos sociais e no mundo.

\section{Reflexões históricas sobre a Alteridade}

Dentro do processo colonialista do pensamento ocidental a relação epistemológica e discursivamente hegemônica tinha entre seus objetivos primordiais tornar as relações da diferença em algo homogêneo e constantemente eurocêntrico, com uma única temporalidade linear, pautada sempre na ideia de origem e essência. O que para Stuart Hall (2011) foi a pós-modernidade uma das responsáveis por provocar descentramentos irremediáveis e rupturas que atingiram não somente os sujeitos, mas seus lugares sociais e culturais no mundo, causando uma complexa "crise de identidade", ou identificação como Stuart Hall mesmo prefere denominar.

Somando-se o processo da crise identitária; da ampliação da ideia ou do conceito de cultura; do reconhecimento sobre as relações da diferença cultural; dos valores nas literaturas - a partir da problematização do próprio conceito de literatura; das complexidades e importâncias de outras epistemologias e seus processos de interrogações sobre o privilégio logrado pela metafisica ocidental e suas narrativas de subjetividades originárias, conforme destacou Homi K. Bhabha (1998) e, de todas as complexas e 
amplas questões teóricas que questionaram e problematizaram o poder eurocêntrico no mundo, sobretudo, na pós-modernidade, têm-se com isso, consequentemente, outras formulações epistemológicas e metodológicas que nos oferecem possibilidades de reconsiderar a importância e a potência que esboçam a heterogeneidade. Heterogeneidade presente, principalmente nas histórias locais, na força não aparente do reconhecimento da alteridade e, especialmente, de inquirir o discurso hegemônico que silenciou e até hoje tenta calar outros discursos que são diferentes ao do colonizador.

Assim, ao contrário de todo o discurso e representação histórica construído desde que surgiu o conceito de Amazônia - estruturada como bem sabemos a partir de narrativas sobre o chamado Novo Mundo e a ideia do eldorado - e toda uma visão homogeneizadora, generalizadora e estereotipada sobre esta geografia e os sujeitos amazônidas, é preciso reconhecer que parte das narrativas e poéticas contemporâneas amazônidas estão continuamente reafirmando outras perspectivas sobre a Amazônia, de modo a promover um complexo deslocamento discursivo da visão homogênea, eurocêntrica e histórica sobre o próprio território amazônico e os sujeitos amazônidas.

No entanto, é necessário destacar também que, por meio, por exemplo, de narrativas que estão contribuindo diretamente nos procedimentos de territorialização e reterritorialização situadas fora dos discursos homogeneamente dominantes - estes que foram utilizados como uma das estratégias para capitanear ou afirmar modelo e parâmetro hierárquico, capaz de silenciar a diferença dentro da própria Amazônia - tem-se com essas narrativas e poéticas rupturas que estão imbuídas de poder e valor a partir do próprio reconhecimento da diferença e, por exemplo, da alteridade, ou seja, do reconhecimento do outro como heterogêneo, marcado pelas suas diferenças, mas revestido de valor e, não corporificado por um estereótipo, como preterido pelo discurso do colonizador.

Foram, de certo modo, essas narrativas e poéticas as responsáveis por contribuir nos procedimentos de reconfigurações tanto no reconhecimento do processo da diferença cultural quanto para a abertura de novas compreensões e perspectivas sobre os lugares enunciativos e a alteridade, não como modelo dicotômico, mas como estratégia de resistência, capaz de rasurar esses supostos modelos eurocêntricos. 


\section{A Alteridade na poética do Sudeste do Pará a partir da leitura reflexiva da Antologia Tocantina, organizada por Ademir Braz}

Nas poéticas produzidas nas regiões do sul e sudeste do Pará, geograficamente a região pertencente à Amazônia Oriental, uma das marcas da diferença existente nesta literatura é a ressignificação dos discursos construídos e historicamente impostos como modelo unificado sobre os amazônidas e a paisagem amazônica. Ressignificação esta, diga-se de passagem, não de modo completamente intencional ou para resultar prioritariamente no processo de negação sobre os discursos que foram criados sobre a Amazônia, mas para mostrar quão híbridos e heterogêneos são os sujeitos amazônidas. Não obstante, para compreendermos melhor estas implicações das ressignificações discursivas e também poéticas é preciso levarmos em consideração o que enfatiza Penalva, sobre a identidade cultural, ao ressaltar que,

É preciso incluir nessa discussão sobre identidade cultural nas terras e paragens amazônicas, elementos de instabilidade e movência, que marcam as culturas na contemporaneidade. Em vez de se buscar, como quis Márcio Souza "uma civilização tipicamente amazônica", como se houvesse uma essência amazônica, devemos compreender que a Amazônia, enquanto espaço enorme, continental, portanto, plural por natureza, tem possibilitado diferentes formas de relações do homem com a vida, que significa formas diferentes de imaginários sociais. (PENALVA, 2012, p. 38).

Essas instabilidades e movências aludidas acima por Penalva possibilitaram de certa forma uma espécie de "desorganização dos discursos estabilizados da identidade" (PENALVA, 2012, p. 20) internamente na Amazônia e sobre ela mesma.

No entanto, é imprescindível ressaltarmos que foram esses discursos, organizados sob a insígnia de uma homogeneidade e instituídos a partir do processo de colonização, que, por conseguinte, estiveram sempre imbuídos de estratégias discursivas, de poder unilateral e epistemológica, que buscaram negar a qualquer custo a alteridade. Todo esse processo eurocêntrico sempre buscou com isso originar uma espécie de pseudo-controle, aos quais os limites eram a essencialidade, a homogeneidade para desautorizar e considerar ilegítimos as textualidades e posições que atribuem valores a diferença e a alteridade.

À custa disso, por exemplo, a Antologia Tocantina, uma obra publicada em 1998 que resultou de quase uma década de pesquisa e de muito trabalho empreendido pelo poeta e advogado, Ademir Braz buscou reunir parte da produção poética de escritores e escritoras que ou nasceram ou vivem/viveram em Marabá e, que traz à tona um lócus 
poético que amplia as abordagens a respeito das reelaborações das identidades dessas regiões mostrando a pluralidade e a complexidade existentes nesta parte da Amazônia Oriental.

Em Antologia Tocantina encontra-se a produção poética de vinte e quatro poetas e poetisas marabaenses ${ }^{3}$ com uma totalidade de quase setenta poemas publicados no livro, o que resulta em uma média de três poemas por autor ou autora. Entretanto, um dos marcos da publicação deste livro é a possibilidade de mostrar o potencial propulsor, a partir das diversas temáticas dos poemas. Nessa Antologia é possível encontrar poética sobre a paisagem amazônica, capaz de desnudar e rasurar os discursos que tentaram, ao longo dos anos, cooptar e impor formas de poderes unilaterais e, hierarquicamente construídos sobre a região amazônica.

Discursos estes que quase sempre colocaram a paisagem amazônica como algo que promove uma espécie de determinismo nos sujeitos, na tentativa de ocupar, conforme destacou Penalva (2012), o imaginário local. Ao passo que essas poéticas contribuem significativamente para ressignificar as identidades das/nas amazônias e suas posições históricas, sociais, culturais, políticas e toda a sua dimensão heterogênea e híbrida, como é possível verificarmos no poema intitulado "Conflitos" ${ }^{4}$, de Elena Borges dos Reis,

\section{Conflitos}

Identidade

fotos, impressões digitais, números, passos, rostos, caminhos...

Caminhos, o que são caminhos?

estradas, ideias, religiões, seitas, carimbos, medalhas, profetas, filosofias.

Pensamentos borbulhando no quarto sombrio mas calmo.

Fotos, impressões digitais, números, passos, rostos, caminhos...

Caminhos, o que são caminhos? (BRAZ, 1998, p. 43).

Neste poema, a partir do próprio título, o eu poético apresenta uma dimensão identitária ou de identificação dos sujeitos amazônidas. Assim, o poema coopera para provocar rupturas nas estruturas discursivas até então impostas historicamente como

\footnotetext{
${ }^{3} \mathrm{O}$ termo marabaenses neste caso especificamente se leva em consideração não apenas os autores ou autoras que nasceram em Marabá, mas, também os que aqui viveram ou vivem e que deixaram ou deixam marcas na poética da região.

${ }^{4}$ O poema "Conflitos" foi publicado na Antologia Tocantina, organizada por Ademir Braz, p. 43.
} 
homogêneas e fixas e, postuladas como verdade única sobre estes sujeitos e a região. (REVISAR PONTUAÇÃO)

O eu poético contribui para organizar um processo visando desconstruir esse projeto essencialista sobre os sujeitos e as culturas das Amazônias ao alargar importantes campos simbólicos, entre os quais podemos destacar: estradas, ideias, religiões, seitas, mostrando com isso que na Amazônia as relações e contatos são sempre híbridas, marcando, por exemplo, o rompimento de fronteiras ao pluralizar os substantivos estradas e caminhos, ou mesmo ao referir-se as religiões e seitas.

O poema problematiza a homogeneidade dos discursos construídos historicamente sobre a região, ao flexionar ao longo de todo o poema uma maneira predominante de pluralização verbal (são e borbulhando) e também dos substantivos (fotos, caminhos, estradas, religiões, etc.). De tal modo, que contribui para deixar rastros sobre as representações do eu, que se encontra no poema completamente atravessado por processos híbridos pelas relações de contatos com o outro, ou simplesmente pela presença e abertura de outros caminhos. Neste poema é possível perceber ainda os rompimentos com a compreensão homogênea e essencializada do próprio eu, mostrandonos como são heterogêneos, múltiplos e complexos os sujeitos amazônidas: passos, fotos, rostos e impressões digitais.

A Antologia Tocantina traz em seu corpus uma poética do diverso, capaz de provocar problematizações nas relações discursivas e também dos valores que foram instituídos pejorativamente sobre a paisagem e os sujeitos na Amazônia. O livro rasura o discurso homogêneo e essencializante e coopera para alterar o lugar de enunciação, apresentando o sudeste do Pará como lócus enunciativo.

Outro exemplo é o poema "Zorra", de autoria do poeta Manoel Nunes dos Reis que apresenta uma coexistência da diferença, a partir de seu caráter híbrido, heterogêneo e, sobretudo, ao incorporar o reconhecimento da alteridade.

\section{Zorra \\ Retumbantes tambores \\ Ouro no brilho do sol \\ Orixás e tupis \\ Marabá \\ Castanhais arraiais \\ Curumins cunhatãs}

\footnotetext{
${ }^{5}$ O poema “Zorra” foi publicado na Antologia Tocantina, organizada por Ademir Braz, p. 111.
} 
DOI: 10.47694/issn.2674-7758.v3.i7.2021.147161

Carajás Tocantins

Marabá

Curiós coronéis

Capitães garimpeiros

Muita gente pra lá

- e feliz

- muita gente de cá

pra lá de feliz. (BRAZ, 1998, p. 111).

Esse poema problematiza a concepção homogênea da identidade na Amazônia, imposta historicamente a partir da concepção da tradição ocidental. Nesse caso, a presença de múltiplas territorialidades no poema, como por exemplo, nestes dois versos: Castanhais arraiais// Carajás Tocantins, mostra-nos que as territorialidades amazônicas são múltiplas, o que significa afirmar que o projeto eurocêntrico, que tinha como base primordial o intuito de estabelecer modelo e fixidez para os processos identitários heterogêneos nas Amazônias é impossível acontecer, por conta da heterogeneidade existe aqui.

Outra questão importante no poema "Zorra" é a demarcação de várias identificações, ou seja, categorias que demarcam outras identidades existentes na Amazônia, principalmente em suas condições não estanques, como podemos verificar, por exemplo, nestes versos: Curumins cunhatãs // Curiós coronéis // Capitães garimpeiros. Assim, o poeta ao marcar as diferenças e seus valores heterogêneos dentro do poema, faz com que outros discursos simbólicos sobre a identificação na Amazônia adquirem novos e incessantes sentidos de representações díspares, híbridas e marcadas sempre pela alteridade, ao delinear, por exemplo, categorias de identificações não estanques e homogêneas, tais como: Órixas, Tupis, coronéis, capitães e garimpeiros.

Para compreendermos melhor essa questão da diferença e da identidade, vejamos o que ressalta Kathryn Woodward: "as identidades são fabricadas por meio da marcação da diferença. Essa marcação da diferença ocorre tanto por meio de sistemas simbólicos de representação quanto por meio de formas de exclusão social. A identidade, pois, não é o oposto da diferença: a identidade depende da diferença” (WOODWARD, 2014, p. 40).

Envoltos de importantes questões em torno da diferença e da identidade e dessa relação de dependência entre ambas, é possível perceber que nesta correspondência entre diferença e identidade, contrárias por excelência, a compreensão de uma suposta tradição e da homogeneidade, faz emergir, de maneira fundamental os procedimentos de reconhecimento e de valor da alteridade. No poema "Zorra", e em diversos poemas da Antologia Tocantina, a alteridade, a diferença e os processos de identificações e seu valor 
foram marcados sensivelmente, contribuindo para refutar os estereótipos elaborados historicamente sobre os sujeitos amazônidas. Em vários poemas é possível perceber como estão assinaladas as múltiplas dimensões do outro, por exemplo, ao final do poema:

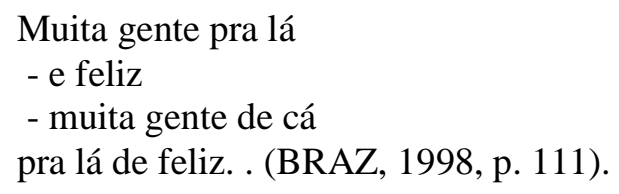

Esse deslocamento - pra lá e pra cá - marca as questões relacionadas às identidades e deixam, de certa forma, indeterminados os lugares, as territorialidades e rasura a suposta essencialidade sobre a paisagem amazônica e os sujeitos amazônidas.

Por conseguinte, as literaturas que foram e vêm sendo produzidas nas regiões do sul e sudeste do Pará, remotamente desde o surgimento da Associação Marabaense de Letras, criada por volta de 1920, ou mesmo pouco antes disso, demarcam outras formas de compreensões discursivas sobre a Amazônia e os sujeitos amazônidas. Essa mesma literatura também passou a circunscrever as dimensões culturais, políticas, sociais e de identificação tanto da paisagem amazônica quanto dos amazônidas, traçando, de certo modo, profundas relações dos aspectos da natureza, não como algo que domina ou forja o destino dos sujeitos amazônidas, mas, uma natureza evidenciada pela sua própria condição híbrida.

Em relação aos sujeitos amazônidas essas literaturas produzidas aqui contribuem para desmitificar a ideia de uma identidade homogênea para os amazônidas. São de certa forma, literaturas que logram rasurar as representações discursivas e históricas produzidas na Amazônia, que foram historicamente todas essencialmente, conforme destaca Penalva, “eivadas do olhar do colonizador” (PENALVA, 2012, p. 25).

\section{A Alteridade na expressão poética de Carles Trocate}

O poeta amazônida Charles Trocate desde seu primeiro livro intitulado Poemas de Barricada aponta para outras formações discursivas sobre a Amazônia, focalizando entre outras questões, a relação de alteridade, as implicações sobre o poder e a exploração econômica na Amazônia, de modo que, desestabiliza um suposto poder hegemônico e eurocêntrico, ao mesmo tempo em que interroga a homogeneidade discursiva imposta na Amazônia. Dessa forma, sua expressão poética contribui para rasurar e desarranjar os discursos sobre a identidade homogênea, produzindo com isso uma expressão poética que reelabora um necessário processo de desconstrução. 
Podemos dizer que a expressão poética de Charles Trocate faz com que seja problematizado e rasurado, ao mesmo tempo o lócus enunciativo e o lócus de enunciação. Neste último caso estão incluídos, por exemplo, outros olhares sobre a paisagem amazônica e o reconhecimento de valor da diferença, como é possível perceber neste poema, retirado de seu livro intitulado Ato Primavera ${ }^{6}$,

\section{Resposta Pública}

\section{Para Rivelino}

Sou real, ambíguo entre as ruas e os combates?

Estou farto da onda do mar, não?

Mas é insuportável não ter o mar

Vivendo nessa cidade de sensações.

Debates tortos sobre a vida

Ignorâncias desdenhando

$\mathrm{O}$ último acontecimento

Lirismo apodrecido!

Vivo esses dias machucado por essas pancadas

[rinocerontes

Um dia, ingovernável será minha loucura

Quando ela chegar quero um lugar

Debaterei esse lugar

Serei esse lugar

A mim que é posto isso, odeio a metafísica

Hoje tão angular na política!

Tenho músculos explorados e toda a classe

[deveriam saber

Mais os piores hematomas

Vão no coração galáxia

Terreno cheio de diagramas e explosões! (TROCATE, 2007, p. 40-41).

Neste poema está outro olhar discursivo sobre a Amazônia, que tem por sua vez o lócus de enunciação imposto pelo colonizador sobre a região totalmente rasurado ao passo que o lócus enunciativo já não é mais o do próprio colonizador ou mesmo os discursos coloniais que foram impostos sobre a Amazônia, mas a voz poética é a de um amazônida, que questiona e problematiza o poder homogêneo e a metafísica angular do pensamento ocidental.

\footnotetext{
${ }^{6}$ Este livro foi publicado em 2007, pela Editora Expressão Popular, de São Paulo.
} 
DOI: 10.47694/issn.2674-7758.v3.i7.2021.147161

O poeta Charles Trocate interroga a centralidade da exploração econômica, política, cultura e social existente no espaço amazônico, como é possível perceber nestes versos,

$$
\begin{aligned}
& \text { Vivo esses dias machucado por essas pancadas } \\
& \text { [rinocerontes } \\
& \text { [...] } \\
& \text { Tenho músculos explorados e toda a classe } \\
& \text { [deveriam saber. (TROCATE, } 2007 \text {, p. 40/41). }
\end{aligned}
$$

Assim, sua poética demarca a territorialidade amazônica ao mesmo instante em que se torna o próprio lugar, ao tomar para si as dores da exploração e da imposição do poder, colocando a voz lírica presente no poema na centralidade da exploração e dos processos de subjugação dos sujeitos amazônidas,

\section{Serei esse lugar}

\section{$[\ldots]$}

A mim que é posto isso, odeio a metafísica (TROCATE, 2007, p. 40-41).

É possível percebemos no poema que mesmo explorado e subjugado a voz lírica questiona, problematiza a exploração, o poder, e com isso tenta resistir a qualquer custo a espoliação do ser e da natureza amazônica. Além disso, implica valor aos sujeitos amazônidas e toda a heterogeneidade existente na geografia material e imaterial na Amazônia. Como isso é possível? Charles Trocate promove poeticamente alterações discursivas sobre o espaço amazônico, as temporalidades existentes nesta região e o reconhecimento do outro, ao nomeá-lo, por meio de uma estratégia poética que contribui para transgredir e contestar todo o projeto homogeneizador sobre a identidade na Amazônia, conforme vemos adiante, nas análises dos poemas.

Ao reconhecer a alteridade e atribuir valor a diferença, a paisagem amazônica deixa de ser vista como a dominadora em relação aos seres amazônidas. Com isso, o poeta faz ruir os processos substanciais que tentaram estabelecer formas de verdades e de identidade nesta região, onde a paisagem estava marcada no discurso do colonizador como um lugar de exuberância, grandiosidade e perversidade e, que supostamente assinalava o destino do homem amazônida. 
Charles Trocate reconfigura os seres amazônidas, marcando a alteridade e fazendo com que sua poética atravesse os discursos essencializantes sobre a paisagem e o próprio ser na Amazônia. Já que, este poeta coloca a paisagem amazônica para além dos elementos folclorizados pelos discursos coloniais, como por exemplo, a supervalorização da floresta amazônica em detrimento dos amazônidas, dos seus rios, dos mitos e lendas, entre outros elementos e, principalmente para a dissociação dos discursos que foram impostos sobre a relação e o silenciamento da alteridade e a elaboração de uma identidade fixa na Amazônia.

Os traços heterogêneos presentes na expressão poética do livro-poema Conversa com Louças, de Charles Trocate, possui uma dimensão voltada para o reconhecimento do outro. Dessa forma, o eu, de Conversa com Louças, é sempre um nós, o diverso marcado pela diferença, rarefeito de uma coletividade, a provocar um descentramento da homogeneidade e da relação com a subjetividade originária, o que faz com que a implicação seja a problematização e o questionamento em torno da ideia de um sujeito logocêntrico. Vejamos a oitava estrofe do livro:

Sobre a culatra ilustrações

Intimamente abraço [rígidas

O horóscopo de outros

[passantes. (TROCATE, 2015, p. 51).

O livro-poema Conversa com Louças está repleto desses outros passantes, como marca da alteridade. Além do mais, contribui para interrogar e delinear outras geografias, ou seja, outros lócus enunciativos. Além disso, Charles Trocate ao problematizar a homogeneização das coisas e dos seres e, ao mesmo tempo fazer com que outras vozes possam quebrar as ilustrações rígidas, possibilita por meio de sua poética outros olhares sobre a região sul do Pará, ampliando múltiplos olhares a respeito dos sujeitos que foram historicamente subalternizados, silenciados e estereotipados pelo discurso eurocêntrico do colonizador.

De certa forma, o poeta Charles Trocate fazer com que sua poética possa rasurar a ideia homogênea dos sujeitos amazônidas que são completamente heterogêneos e reconfigura em vários poemas a paisagem e as temporalidades amazônicas. Esta mesma relação esta perceptivelmente presente na expressão poética deste livro trocatiano, como podemos ver nos versos abaixo:

O que éramos de horizonte 
DOI: 10.47694/issn.2674-7758.v3.i7.2021.147161

Para que alguém se

[orgulhe

Vá ao baile

Com perna só de tão estranho

Que o tempo era. (TROCATE, 2015, p. 52).

Ao lermos os versos acima, podemos verificar que o tempo presente no livro Conversa com louças está atravessado por múltiplas e incessantes temporalidades (éramos-passado; Vá-futuro; Hoje-presente). Ao passo que o poeta problematiza e busca romper com a ideia de uma temporalidade linear (Com perna só de tão estranho/Que o tempo era), tão valorizado pela subjetividade originária, para usarmos aqui uma definição de Homi K. Bhabha (2013) sobre a metafísica ocidental.

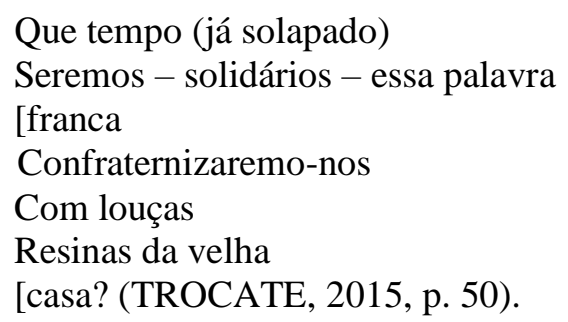

Nessa estrofe o poeta Charles Trocate faz a temporalidade tornar-se salopada, ruir em sua base homogênea, temporalmente definida como unilateral e linear. Além disso, o verbo ser (seremos), pluralizado assinala a alteridade e, quando o poeta interrogar:

\author{
Confraternizaremo-nos \\ Com louças \\ Resinas da velha \\ [casa? (TROCATE, 2015, p. 50).
}

Assim, por meio do processo constante de interrogar o poeta faz com que um jogo de ação seja colocado em prática. O que isso quer dizer? De maneira mais pragmática Charles Trocate questiona as resinas homogêneas, que foram historicamente um dos meios de fixar e estereotipar o outro, ao mesmo tempo me que contribuiu para uma espécie de elaboração binária de compreensão do mundo.

\title{
Considerações finais
}

A expressão poética de Charles Trocate demarca, em vez de uma territorialidade fixa e linear, outras extraterritorialidades rizomáticas. Não para recusar, negar ou mesmo elaborar uma espécie de primazia da fixação homogênea do tempo e também do poder, na Amazônia. É, principalmente, reelaborado temporalidades em dissonância, um nãotempo, a não visar, por exemplo, ser solidificado e ou mesmo solidificador de verdades, 
mas antes de tudo, questionador, para problematizar a linearidade da razão; razão esta, agora para o poeta Charles Trocate, em total desuso.

Na expressão poética de Conversa com Louças é possível compreendermos que o poeta Charles Trocate ao problematizar e questionar a temporalidade linear elaborada pela metafísica ocidental - para criar uma espécie de verdade e dominação sobre os demais povos - entrelaça múltiplas temporalidades em sua poética e, com isso provoca rasuras no processo discursivo que foi imposto na Amazônia.

Nesta expressão poética tanto a temporalidade como a própria espacialidade amazônica perpassam pela marcação da diferença e rompe com estereótipos e as ideias exóticas sobre os sujeitos amazônidas, pois a voz lírica presente neste livro-poema mostra-nos que o poeta reelabora outras maneiras poéticas de compreender os processos híbridos e heterogêneos presentes na geografia amazônica e encara o tempo presente.

Marcando descontinuidades, Charles Trocate faz com que a presença de um possível tempo-linear em seu livro-poema Conversa com louças seja problematizado, ao fazer sua poética atua no processo de interrogação da homogeneização dos sujeitos heterogêneos na Amazônia e também do próprio território amazônico. De tal modo que sua expressão poética coopere para provocar rasuras necessárias ao despertencimento representacional de uma unidade imediata, pois, o poeta rasura possíveis conexões com qualquer que seja o tempo serial e linear, responsável por provocar uma fixidez totalmente homogênea.

\section{Referências}

BHABHA, Homi K. O Local da Cultura. Tradução: ÀVILA, Myriam; REIS, Eliana Lourenço de L.; GONÇALVES, Gláucia Renate. Belo Horizonte: Editora UFMG, 1998.

BRAZ, Ademir. Antologia Tocantina. Marabá: Grafecort, 1998.

HALL, Stuart. A identidade cultural na pós-mordenidade. Tradução: Tomaz Tadeu da Silva e Guacira Lopes Louro. 11 ed. Rio do Janeiro: DP\&A, 2011.

PENALVA, Gilson. Identidade e hibridismo cultural na Amazônia brasileira: um estudo comparativo de Dois Irmãos e Cinzas do Norte, de Milton Hatoum e A Selva, de Ferreira de Castro. (Inédita) 2012.

WOODWARD, Kathryn. Identidade e diferença: A perspectiva dos Estudos Culturais. 14 ed. Petrópolis/ RJ: Vozes, 2014. 
DOI: 10.47694/issn.2674-7758.v3.i7.2021.147161

SPIVAK, Gayatri Chakravorty. Pode o Sulbaterno Falar?. Tradução: Sandra Regina Goulart Almeida, Marcos Pereira Feitosa e André Pereira Feitosa. Belo Horizonte: Editora UFMG, 2014.

TROCATE, Charles. Ato Primavera. São Paulo: Expressão Popular, 2007. 1993. Marabá/PA: Editorial Iguana, 2015. 